\title{
Early failure of transcatheter aortic valves: A timely warning!
}

\author{
Manuel J. Antunes, MD, PhD, DSc
}

\author{
From the Center of Cardiothoracic Surgery, University Hospital and Faculty of Medicine, Coimbra, Portugal. \\ Disclosures: Author has nothing to disclose with regard to commercial support. \\ Received for publication Dec 25, 2016; accepted for publication Jan 5, 2017; available ahead of print Feb 24, \\ 2017. \\ Address for reprints: Manuel J. Antunes, MD, PhD, DSc, Centro de Cirurgia Cardiotorácica, Hospitais da Uni- \\ versidade, 3000-075 Coimbra, Portugal (E-mail: antunes.cct.chuc@ sapo.pt). \\ J Thorac Cardiovasc Surg 2017;153:e95-6 \\ $0022-5223 / \$ 36.00$ \\ Copyright (C) 2017 by The American Association for Thoracic Surgery \\ http://dx.doi.org/10.1016/j.jtcvs.2017.01.025
}

Transcatheter aortic valve replacement (TAVR) - or transcatheter aortic valve implantation (TAVI), as it is termed in Europe-has become a well-established alternative to surgical aortic valve replacement for some patient subsets. Initially TAVR (TAVI) was indicated only for patients with contraindications to or prohibitive risk for surgery, and on the basis of the favorable results recorded in these circumstances, it rapidly (in my view, too rapidly) gained the enthusiasm of both the cardiologic and the surgical fraternities, especially the former, and was soon used for patients at lesser risk and even those with low surgical risk. The percutaneously implanted prostheses used so far, however, which are generally modeled from the surgical bioprostheses, have not yet stood the test of time and some have even been abandoned, as clear proof of their inappropriateness. This is in contrast to most valves currently used in classic surgical aortic valve replacements, which apart from minor modifications have been around for decades and have a highly predictable durability. Durability is in fact the remaining and most pertinent question about the percutaneous valves.

Scattered information about structural complications in percutaneous valves has been published. ${ }^{1,2}$ The large series reported are usually sparse in details, and most important journals are highly restrictive in the publication of case reports. There is thus no clear idea currently of the incidence of structural failure of these prostheses. This in my opinion is why the article published in this issue of the Journal by Summers and colleagues ${ }^{3}$ from the Cleveland Clinic assumes especial relevance, although this was not the declared intention. Summers and colleagues ${ }^{3}$ describe and discuss 3 mechanisms of early failure of transcatheter aortic valves: valve thrombosis, cusp rupture, and accelerated calcification, with each exemplified by the description of a case. Each of these is also a well-known complication of the classic surgical bioprostheses, usually occurring late after implantation, although early failures are also known to occur occasionally.

Although the issue is not openly conceded, the characteristics of the materials used by the manufacturers of

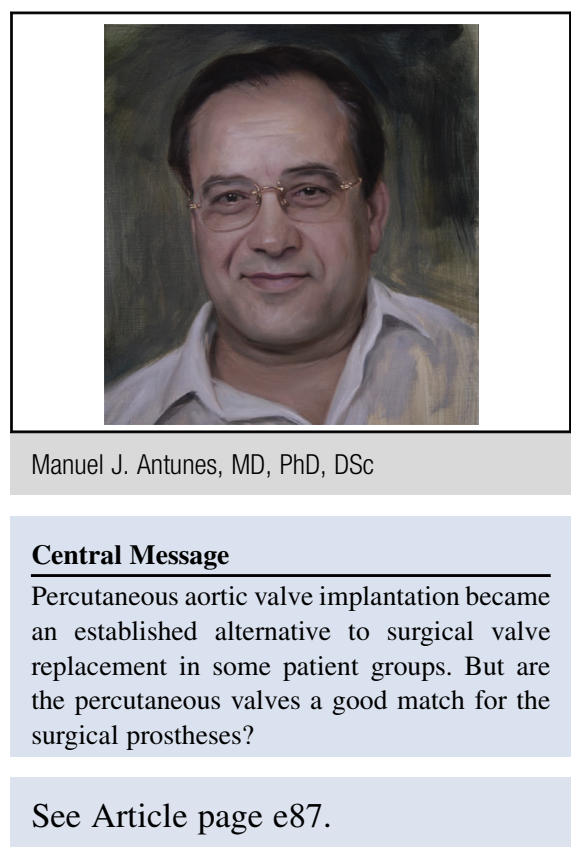

percutaneous prostheses do not exactly match those used in surgical prostheses, especially with regard to the pericardium. Expectations of identical durability may therefore not be warranted. Furthermore, for a surgeon such as I, with 40 years of experience with bioprostheses and used to strong recommendations to avoid distortion as much as possible, it is difficult to foresee the consequences that the crimping of the percutaneous prostheses and positioning in asymmetric annuli will have with respect to their durability.

The report by Summers and colleagues ${ }^{3}$ thus comes at an appropriate time, because the extension of use of percutaneous implantation of aortic valves to patients at lower risk and to young patients raises justified concerns. In the cases reported in this manuscript, structural failure occurred four, three and five years after implantation, respectively. In the absence of more comprehensive reports and series, it is difficult to ascertain whether the percutaneous valves are at greater risk of structural failure by comparison to the surgical valves. As a matter of fact, little is known about the fate of TAVR (TAVI) devices beyond 5 years. ${ }^{4}$ We must naturally wait longer before conclusions can be drawn. Reports like that of Summers and colleagues, ${ }^{3}$ however, surely should trigger some caution with regard to attempts to extend the indications to lower-risk patient groups, especially to the younger population for whom extended durability is fundamental. 
In a paper presented at the EuroPCR conference 2016, Dvir and colleagues, from Vancouver, Canada, and Rouen, France, suggested that half of TAVR valves may degenerate within 10 years (median time to degeneration, 61 months), a performance clearly inferior to that expected from classical surgical prostheses. The potential feasibility of a valve-invalve procedure when the first prosthesis fails could be reassuring, but this method may not work for repeated failures. Also, Bentham and colleagues ${ }^{5}$ reported early failure of percutaneous valves implanted within bioprosthetic tricuspid tissue valve replacements. Finally, the preferential surgical use of bioprostheses versus mechanical valves in young patients, often justified by these newer approaches, has not been validated in surgical series.

In conclusion, excessive enthusiasm for these new technologies may lead to disaster. As I wrote some time ago in another editorial commentary, ${ }^{6}$ "Let us promote innovation but keep the feet on the ground; let us look to the future but not forget the past; it is essential to stay within reality while maintaining the dream"!

\section{References}

1. Mylotte D, Andalib A, Thériault-Lauzier P, Dorfmeister M, Girgis M, Alharbi W, et al. Transcatheter heart valve failure: a systematic review. Eur Heart J. 2015;36: 1306-27.

2. Mylotte D, Piazza N. Transcatheter aortic valve replacement failure: déjà vu ou jamais vu? Circ Cardiovasc Interv. 2015;8:e02531.

3. Summers MR, Cremer PC, Jaber WA. Three mechanisms of early failure of transcatheter aortic valves: valve thrombosis, cusp rupture, and accelerated calcification. J Thorac Cardiovasc Surg. 2017;153:e87-93.

4. Arsalan M, Walther T. Durability of prostheses for transcatheter aortic valve implantation. Nat Rev Cardiol. 2016;13:360-7.

5. Bentham J, Qureshi S, Eicken A, Gibbs J, Ballard G, Thomson J. Early percutaneous valve failure within bioprosthetic tricuspid tissue valve replacements. Catheter Cardiovasc Interv. 2013;82:428-35.

6. Antunes MJ. Minimally invasive valve surgery (reality, dream or utopia?). J Heart Valve Dis. 1998;7:358-9. 